\title{
Research Paper \\ Comparison of Self-efficacy and Loneliness between Community-Dwelling \& Institutionalized Older People
}

\author{
Mohammad Heidari ${ }^{1},{ }^{*}$ Mansureh Ghodusi Borujeni ${ }^{2}$, Ladan Naseh ${ }^{3}$
}

1. Department of Nursing, School of Nursing and Midwifery, Shahrekord University of Medical Sciences, Shahrekord, Iran.
2. Young Researchers Club, Abadeh Branch, Islamic Azad University, Abadeh, Iran.
3. Department of Adult Health Nursing, School of Nursing and Midwifery, Isfahan University of Medical Sciences, Isfahan, Iran.

dtation: Heidari M, Ghodusi Borujeni M, Naseh L. [Comparison of Self-efficacy and Loneliness between Community-Dwelling \& Institutionalized Older People (Persian)]. Iranian Journal of Ageing. 2016; 11(4):142-151. http://dx.doi.org/10.21859/sija-1101142

doi : ${ }^{\text {: }}$ http://dx.doi.org/10.21859/sija-1101142

Received: 08 Oct. 2015 Accepted: 28 Jan. 2016

Key words: Self efficacy, Loneliness, Elderly, Nursing homes

\begin{abstract}
A B S T R A C T
Objectives Today, aging has become a global phenomenon, and attention to its problems is a social necessity. In this age, self-efficacy is associated with psychological dimensions like loneliness. Considering healthy aging as a right for every human highlights the importance of aging phenomenon, prevention of older people problems, and finally presents a better caring service to this vulnerable group. Also, it made the promotion of self-efficacy level and psychological aspects of older people the purposes of health system authorities of the society. This research aimed to study self-efficacy and loneliness between the older people residing in nursing homes and those who live with their families in Shahrekord, Iran.

Methods \& Materials It was cross-sectional study. The samples comprised 100 women and men aged 60 years old and over. The study subjects were recruited by convenience sampling method. Data collection tools were 3-part questionnaire of Sherer self-efficacy and loneliness feeling questionnaire. For data analysis, we used independent t-test, analysis of variance (ANOVA), and the Spearman correlation coefficient. The statistical analyses were conducted by SPSS version 16 .

Results The results showed that most participants in both groups were women ( $n=40,80 \%)$. The mean (SD) age of the subjects living with their families was 75.58 (8.22) years and for those living in nursing homes was $77.78(7.93)$ years. The mean (SD) score of self-efficacy in the elderly living with their families (51.76[11.48]) was more than the elderly residing in nursing homes (48.44[5.26]). Based on the results, self-efficacy had a significant association with employment status and satisfaction with family members (in older adults living with their families). In addition, significant associations were observed between self-efficacy and variables of age, residence place, and satisfaction with nursing home. There was also a significant relationship between loneliness and variables of educational level and satisfaction with nursing home. Our study showed that the degree of loneliness in the elderly people residing in nursing homes is higher (121.36[11.01]) compared to the elderly living with their families (120.94[24.25]). Moreover, there was a reverse and significant relationship between all dimensions of loneliness with self-efficacy in older adults living with their families ( $P=0.001)$.

Conclusion With regard to the low mean score of self-efficacy of older adults residing in nursing homes, the authorities of nursing homes should pay attention to the needs of older adults and provide general education about promoting the tradition of caring older people by their families. Finally, with regard to the results about the association of self-efficacy with loneliness, self-efficacy assessment should be considered one of the effective factors in psychological dimensions of the people and a way to support the self-care of older adults because promoting self-efficacy will result in managing stress and improving the mental health.
\end{abstract}




\title{
مقايسه خودكار آمدى و احساس تنهايى در سالمندان ساكن و غيرساكن آسايشكًاه سالمندى
}

\author{
محمد حيدرى'؛ "منصوره قدوسىبروجنى'، لادن ناصح"

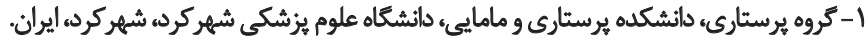

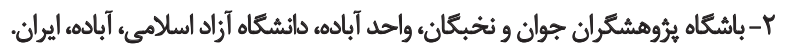

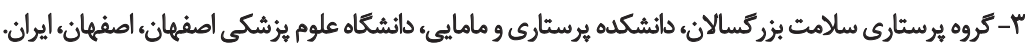

\begin{abstract}
حكSد

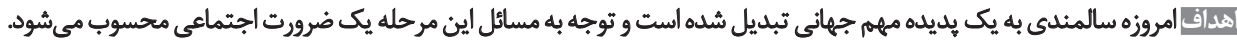

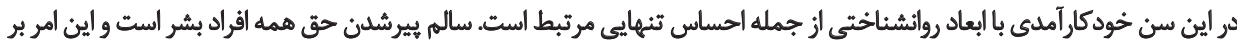

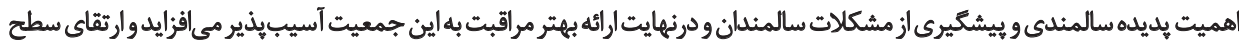

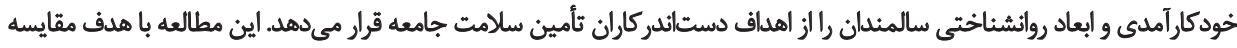

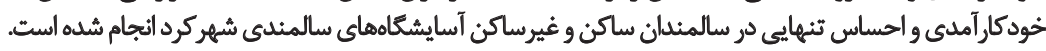

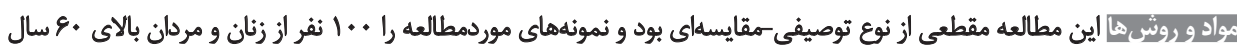

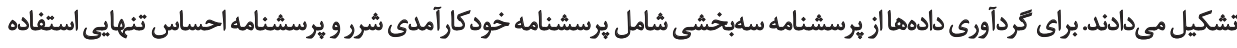

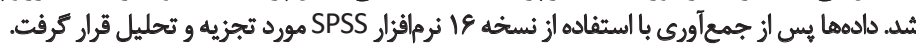

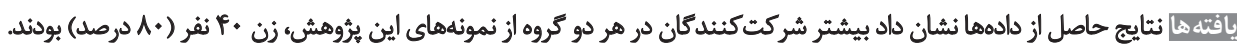

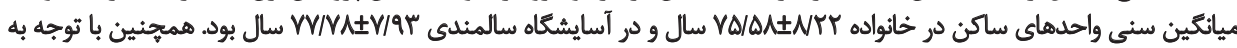

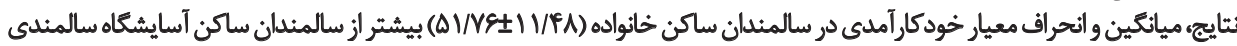

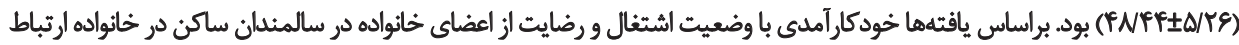

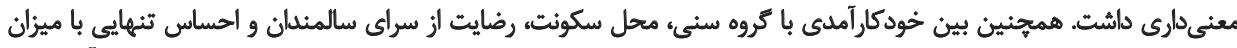

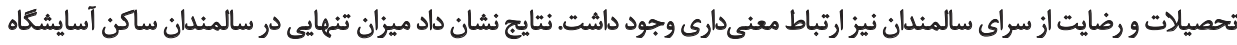

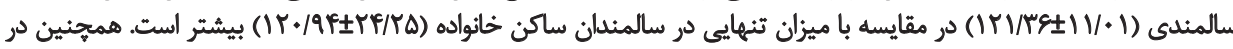

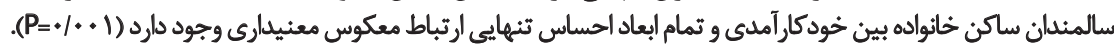

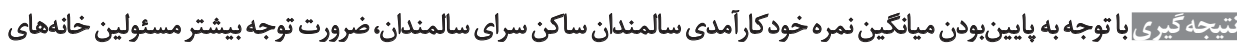

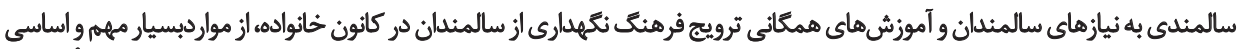

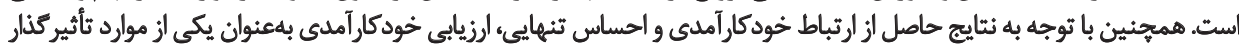

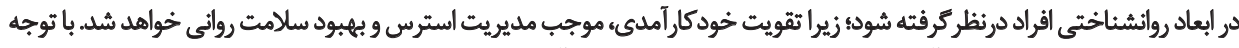

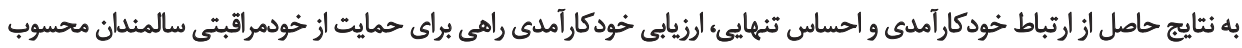

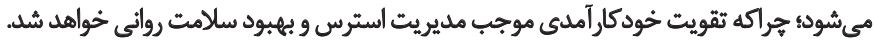

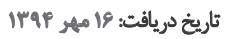

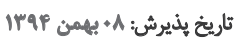

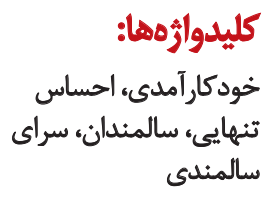

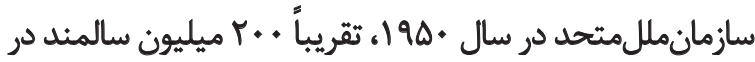

dater

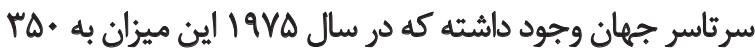

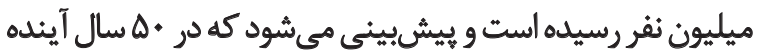

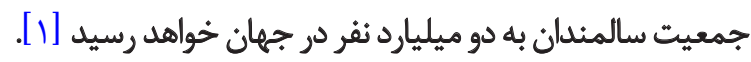
با توجه به افزايش شاخص اميدبلهزندكى در ايران براساس

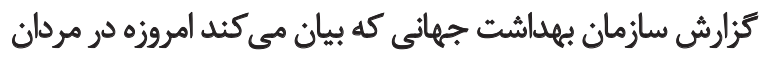

سالمندى فرايندى طبيعى و يكى از مراحل رشد و تكامل

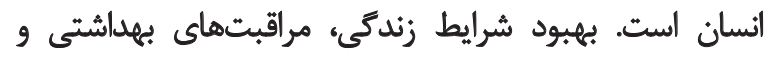

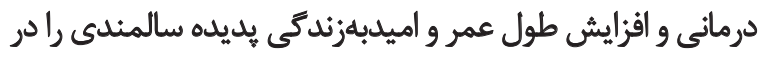

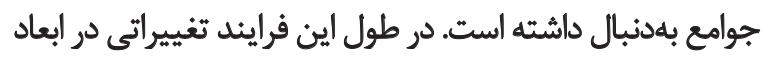

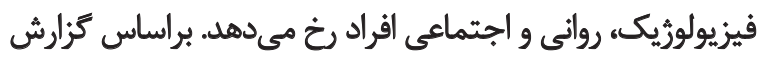


يديده سالمندى و ييشگيرى از مشكلات سالمندان و درنهايت،

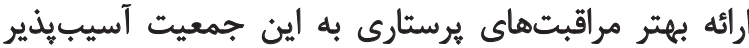

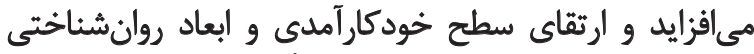

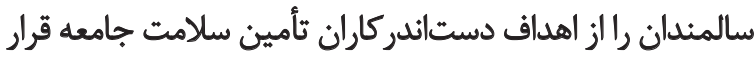
مى دهد [N]]. ازآنجايى كه مناطق مختلف شهرى و وروستايى از

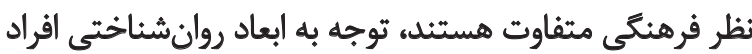

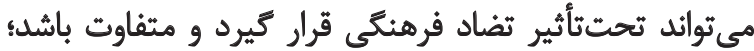

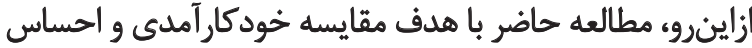

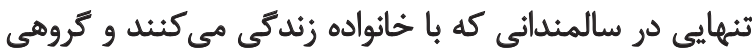

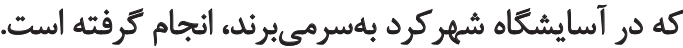

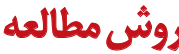

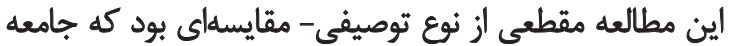

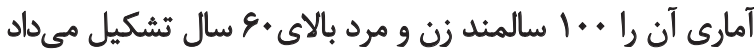

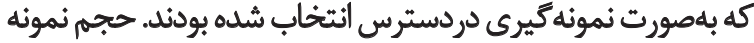

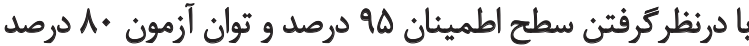

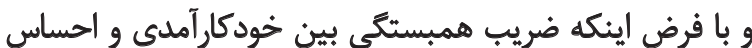

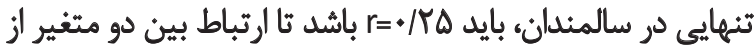

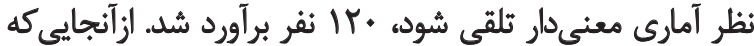

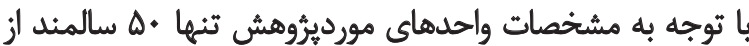

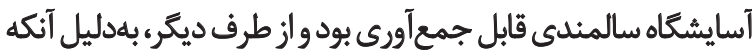

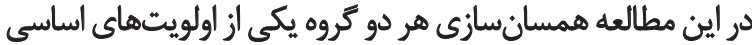

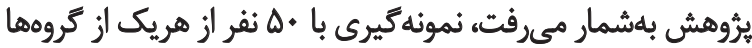

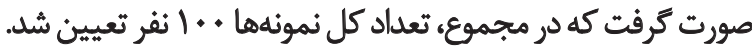
اين سالمندان يا همراه اعضاى خانواده زندكى مي كردند يا در

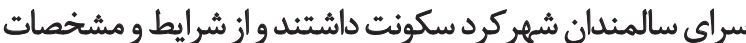
لازم براي شركت در مطالعه برخوردار بودئند

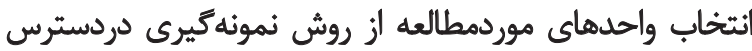

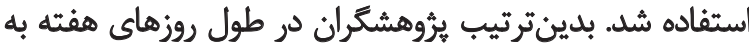

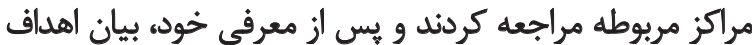

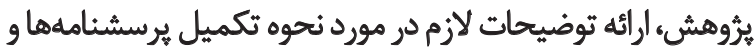

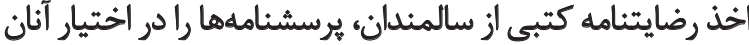

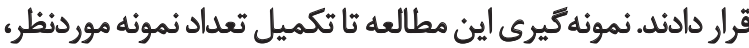

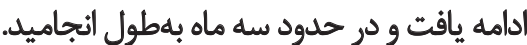

لازم بهذكر است كه يرُوهشَّران در اين مطالعه براي انتخخاب

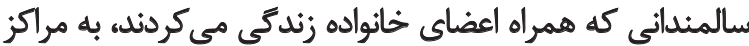

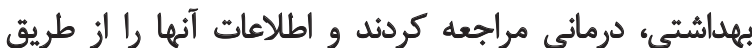

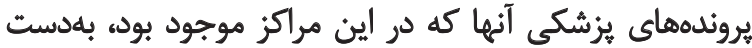

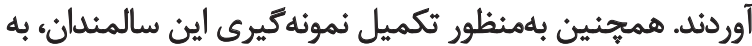

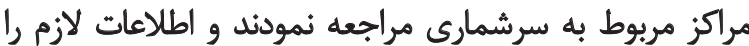

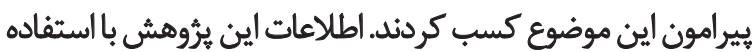

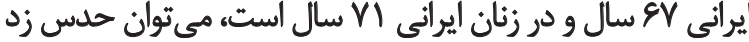

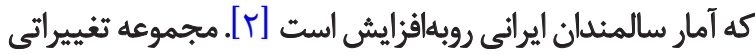

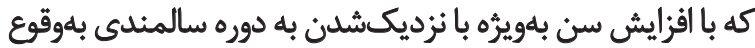

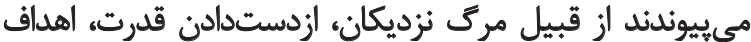

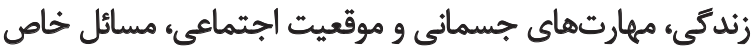

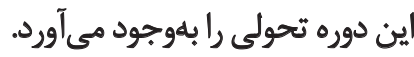

همجينين با افزايش سن سالمندى، تغييراتى در ابعاد مختلف

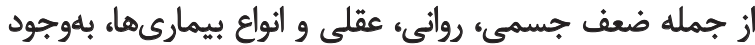

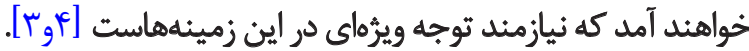

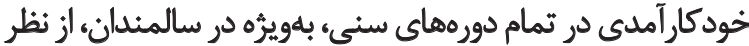

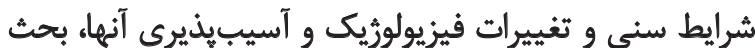

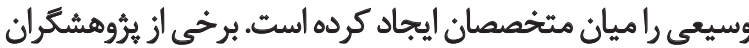

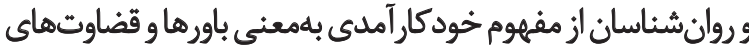

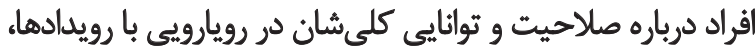
موقعيتهاي تنشزاو تهلديدكنينده استفاده كردماند.

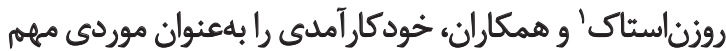

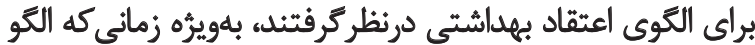

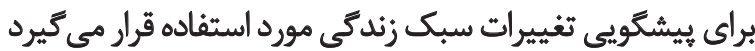

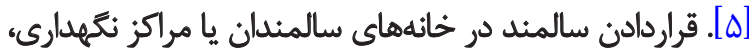

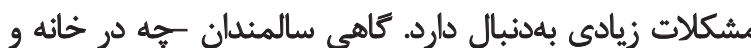

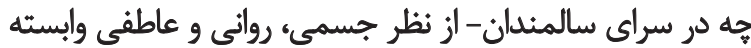

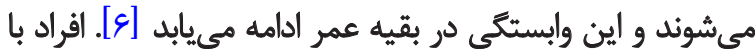

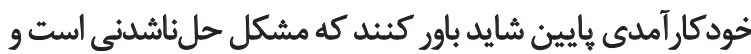

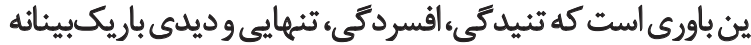

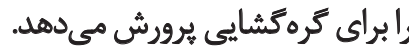

خودكارآمدى از جمله متغيرهايى است كه بررسى ارتباط آن

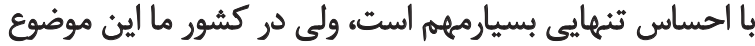

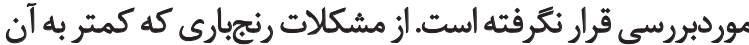

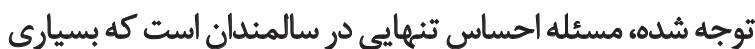

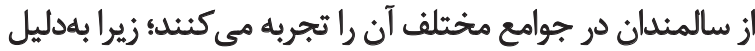

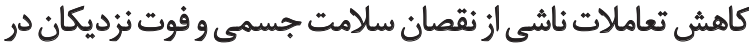

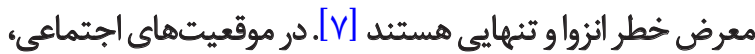

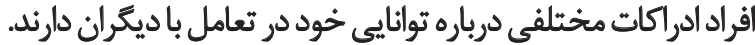

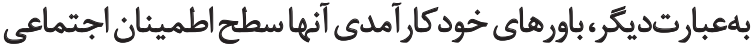

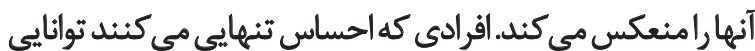

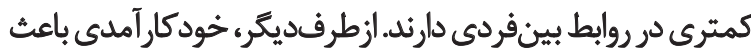

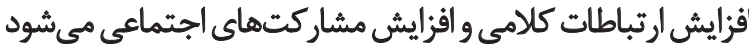

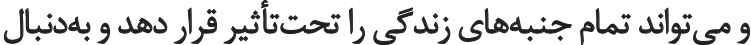
افزايش تعاملات اجتماعي، از احساس تنهاييى آنهابكاهد سالم بييرشدن حق همه افراد بشر است و اين امر بر اهميت 
آمارى تى مستقل، آنوواو ضريب همبستكى اسييرمن استفاده شد.

يافتها

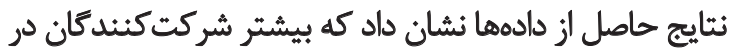

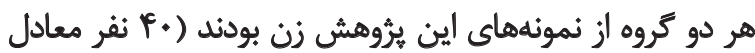

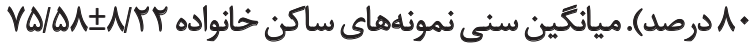

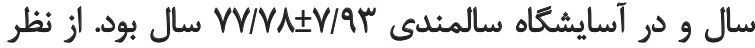

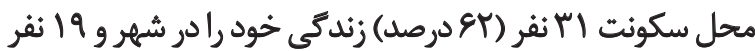

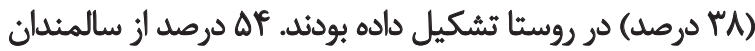

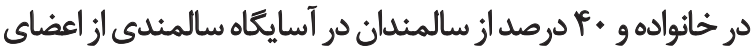

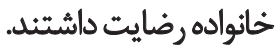

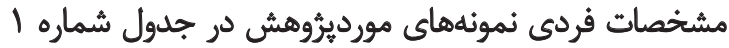

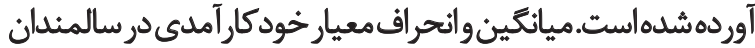

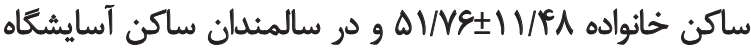
سالمندى F FFF

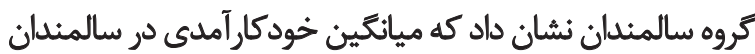

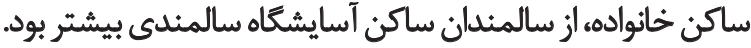

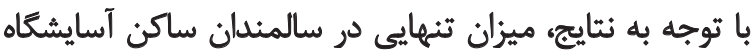

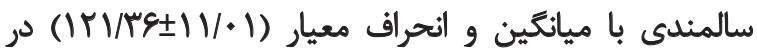

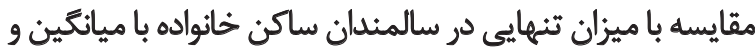

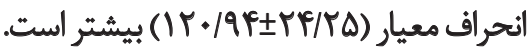

شاخصهاى توصيفى احساس تنهايى به تفكيك محل سكونت

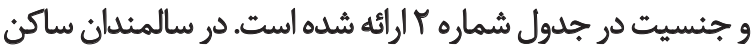

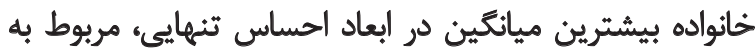

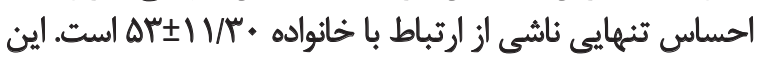

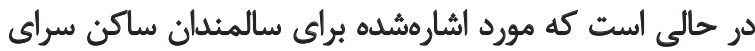

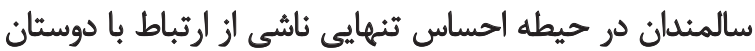

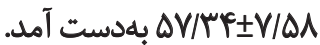

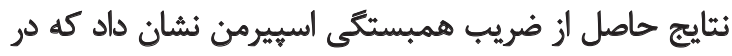

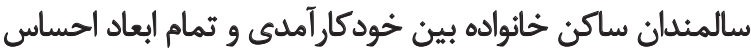

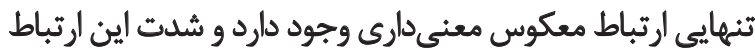

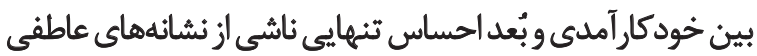

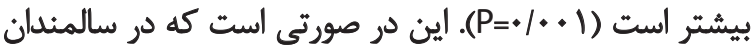

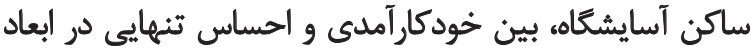

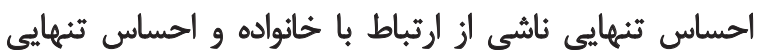

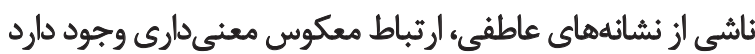

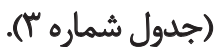

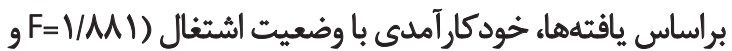

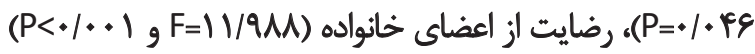

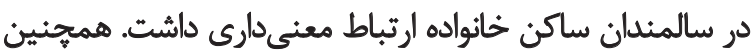

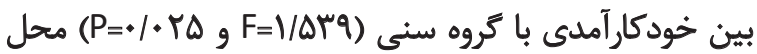

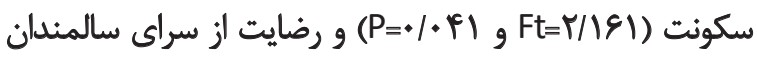

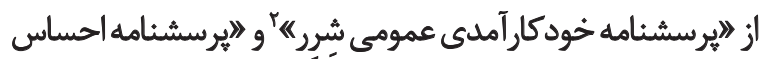
تنهايى "'، جمع آورى كرديد.

هرسشنامهها شِرِر شامل سؤالات مربوط به مشخصاتى مانئد

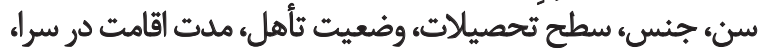

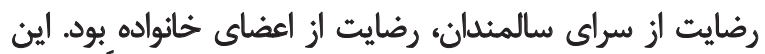

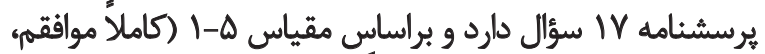

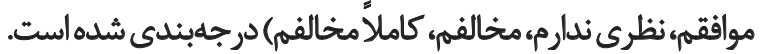

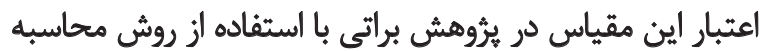

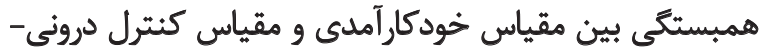

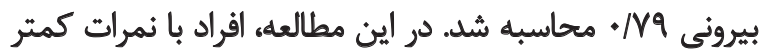

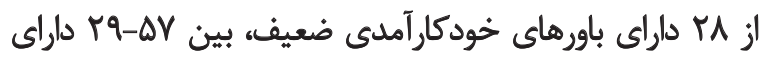

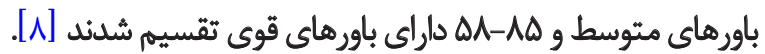
يرسشنامه احساس تنهايى در سال \& ع با، توسط دهشيرى و

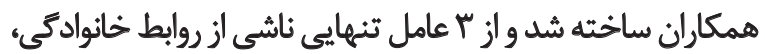

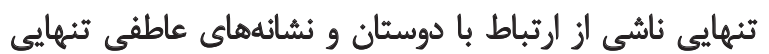

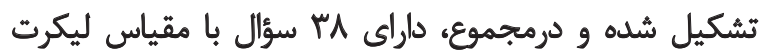

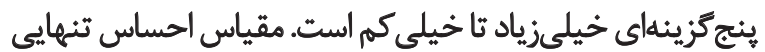

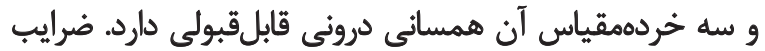

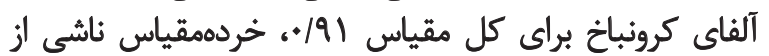

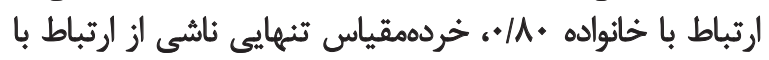

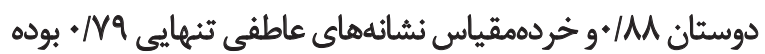

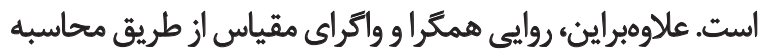

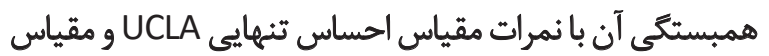

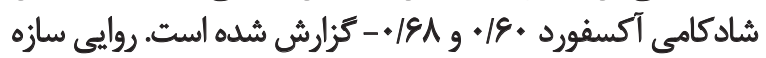

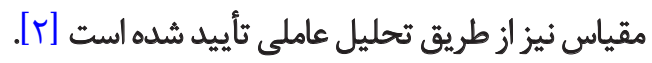

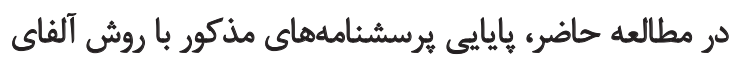

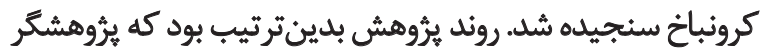

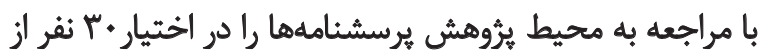

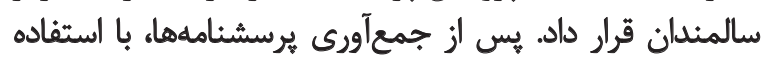

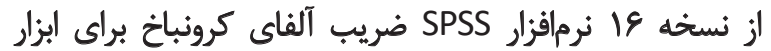

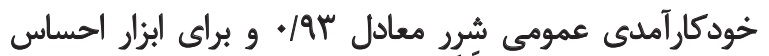

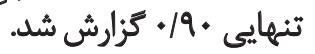

مشخصات نمونههاى مورديثوهش عبارت بود ازئ سكونت در سرا حداقل بهمدت 9 ماه مثوالى، داشتن •و سال و و بالاتر، نداشتن

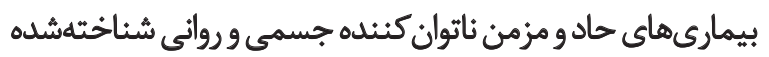

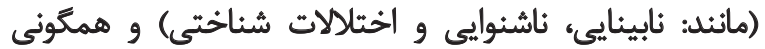

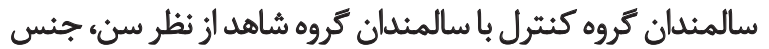

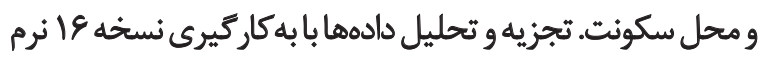

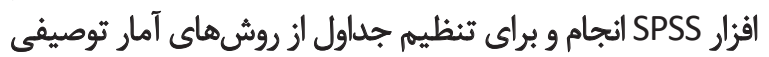

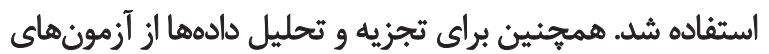

2. Scheerer Efficacy Questionnaire

3. Loneliness questionnaire 
جدول ا. توزيع فراوانى اطلاعات جمعيتشناختى سالمئدان هر دو كروه.

\begin{tabular}{|c|c|c|c|}
\hline فراوائي (درصد) در سالمندان ساكن در آسايشكاه سالمندى & فراوانى (درصد) در سالمثدان ساكن در & \multicolumn{2}{|c|}{ متغيرها } \\
\hline $\begin{array}{l}1 \cdot\left(r_{*}\right) \\
r \cdot(\lambda \cdot)\end{array}$ & $\begin{array}{l}i \cdot(r \cdot) \\
r+(\lambda \cdot)\end{array}$ & مرن & جنس \\
\hline $\begin{array}{c}A(19) \\
M(Y \&) \\
19(r A)\end{array}$ & $\begin{array}{l}M(Y Y) \\
M(Y S) \\
1 \&(T Y)\end{array}$ & $\begin{array}{l}\varepsilon \cdot-8 q \\
v \cdot-\lambda \cdot \\
\Lambda \cdot \geq\end{array}$ & سن \\
\hline $\begin{array}{l}I r(T \&) \\
g(I T) \\
r(A) \\
r Y(\Delta F)\end{array}$ & 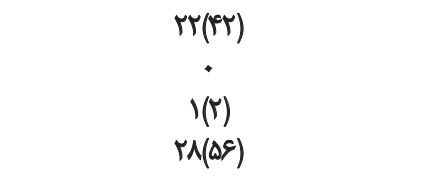 & همسر فوتشلهد مطرد & وضعيت تأهل \\
\hline $\begin{array}{c}\operatorname{PA}(q \varepsilon) \\
I(T) \\
I(T)\end{array}$ & $\begin{array}{l}\mu r(A)) \\
g(I Y) \\
19(Y A)\end{array}$ & زيردييلم ديواد & سطح تحصيلات \\
\hline $\begin{array}{l}\text { MI(gY) } \\
19(\mathrm{YA})\end{array}$ & $\begin{array}{l}1(T) \\
M(E Y)\end{array}$ & 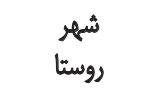 & هحل سكونت \\
\hline $\begin{array}{l}I f(r A) \\
\cdot(\cdot) \\
r \Delta(r \cdot) \\
I(r)\end{array}$ & $\begin{array}{l}r A(\Delta S) \\
V(I F) \\
A(I A) \\
g(I T)\end{array}$ & 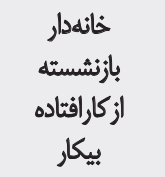 & وضعيت اشتثال \\
\hline $\begin{array}{l}r+\left(r_{*}\right) \\
1 \Delta\left(r_{*}\right) \\
1 \Delta(r \cdot)\end{array}$ & $\begin{array}{l}\left.(\Delta)^{F}\right) T Y \\
\text { G(M) } \\
\mid F(Y A)\end{array}$ & تاحلودير بلى & أغضاي خائواده ازي \\
\hline $\begin{array}{l}r \Delta(\Delta \cdot) \\
g(I r) \\
19(r A)\end{array}$ & - & تاحدودير بلى & رضايت ازئن سراى \\
\hline
\end{tabular}

㿠

جدول ץ. شاخصهاى توصيفي احساس تنهايي به تفكيك محل نتكبدارى و جنسيت.

\begin{tabular}{|c|c|c|c|c|c|}
\hline \multirow{2}{*}{ درصد } & \multirow{2}{*}{ تعداد } & \multicolumn{2}{|c|}{ احساس تنهايى } & \multirow{2}{*}{ جنسيت } & \multirow{2}{*}{ محل نتههدارى } \\
\hline & & انحراف معيار & مياتكين & & \\
\hline$r$. & 1. & $W \cdot \Delta$ & $\| v / M$ & 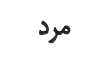 & \multirow{2}{*}{ ساكن سراى سالمندان } \\
\hline A. & f. & $1 \cdot|A|$ & $\mid M T / \Delta \Delta$ & زن & \\
\hline$r$. & 1. & $r+119$ & $11+10$ & مرد & \multirow[t]{2}{*}{ ساكن خانوادهها } \\
\hline A. & f. & refeq & ITY/VD & زن & \\
\hline
\end{tabular}

几 
جدول ץ. ارتباط بين ابعاد احساس تنهايع با خودكارآمدى در هر دو مروه از سالمثدان.

\begin{tabular}{|c|c|c|c|c|}
\hline احساس تنهايي & الحساس تنهايى ناشى از & نشائه تنهائ عاطفى ناشى از & الزساس تنتهايى در بُعد ناشى & \\
\hline ضريب همبستكّي & ضريب همبيتكئى & ضريب همبستّكى أسييرمن & ضريب همبستكى اسيرير & \\
\hline $\begin{array}{l}-r_{s i}=*\left(\Delta r^{\prime \Delta}\right. \\
P_{l=*}=*+*\end{array}$ & $\begin{array}{l}-r_{s 1}=* / / T_{p} \\
P_{1}=* / *+1^{*}\end{array}$ & $\begin{array}{l}-r_{s 1}=+\mid \Delta E V \\
P|=* 1+*|^{*}\end{array}$ & $\begin{array}{l}-r_{s !}=+(4 A) \\
P \mid=+1+*)^{*}\end{array}$ & خودكارآملى سالمندان ساكن \\
\hline $\begin{array}{l}\mathbf{r}_{B Y}=+/ 4 I Y \\
P Y=. / * 1\end{array}$ & $\begin{array}{l}r_{s t}=+|\Delta T| \\
P_{Y}=1 . .1\end{array}$ & $\begin{array}{l}-r_{s Y}=+1 \Delta S Y \\
P Y=.1 . .)^{*}\end{array}$ & $\begin{array}{l}-r_{s r}=* / M V \\
P Y=.1 . .1\end{array}$ & خودمارآملى سالمندان ساكن \\
\hline
\end{tabular}

ㄴ

تركى و همكاران [9] و كالآكان و همكاران [. [ ] خودكارآمدى

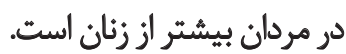

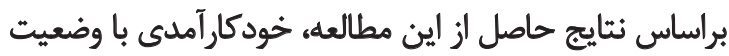

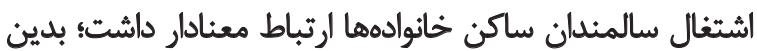

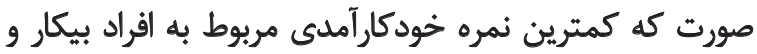

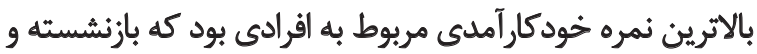

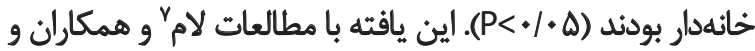

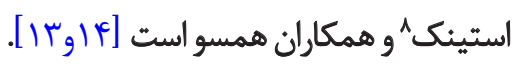

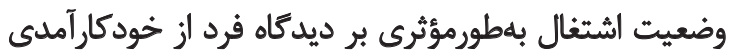

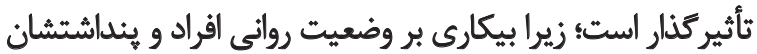

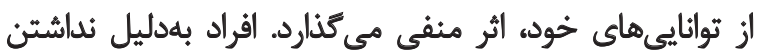

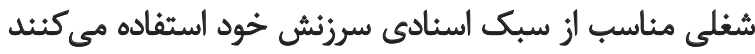

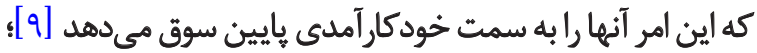

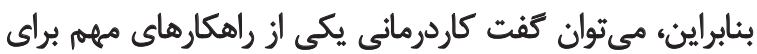

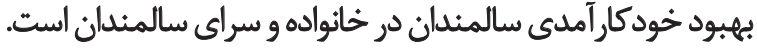
نتايج اين مطالعه اينكونه نشان داد كه در سالمندان ساكن

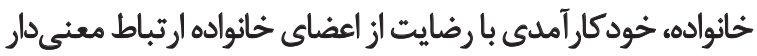

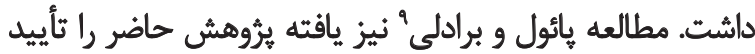

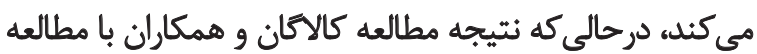

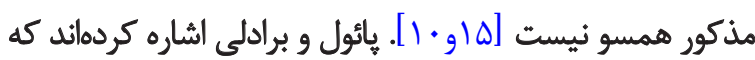

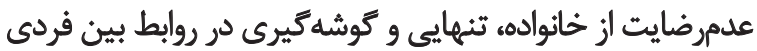

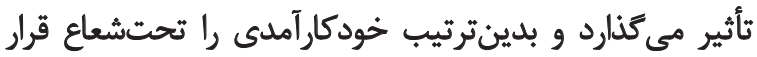

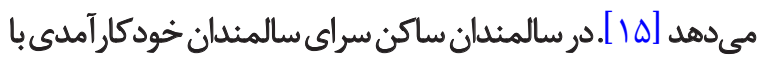

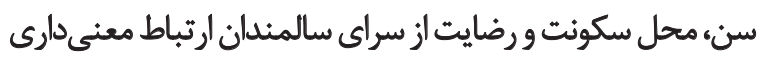

\section{Callaghan}

7. Lam

8. Steinke

9. Paul ans Bradley

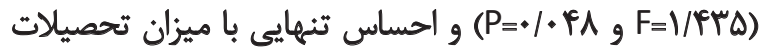

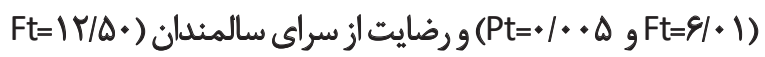
ويكر ديكر نيز در جدول شماره f آ آورده شده است.

ثب

يافتههاى اين مطالعه نشان داد كه بين سالمندان ساكن خانه

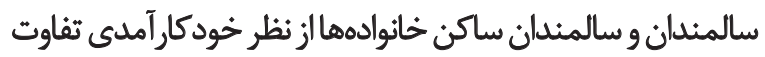

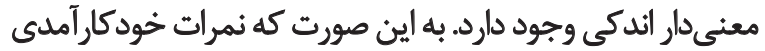

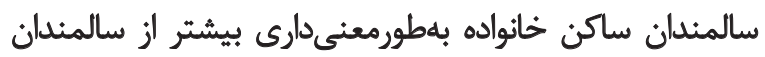

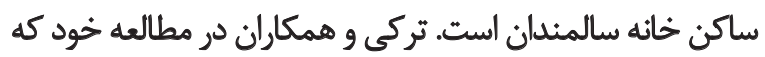

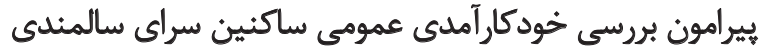

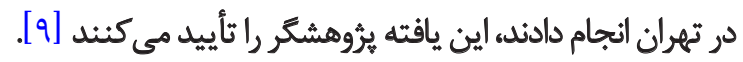
بديهي است عوامل متعددى در كاهش خودكار آمدى سالمندان

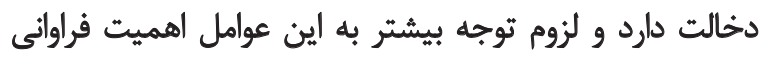

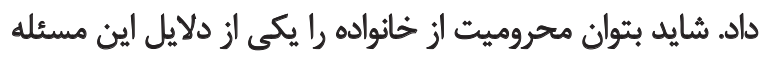

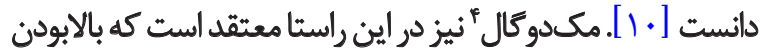

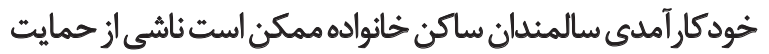

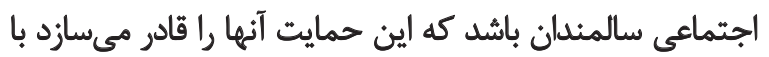

كاهش كاركردهاى جسمى و روانىشان بهتر كنار آيند [ [1 ]

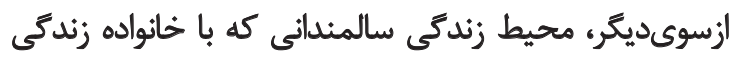

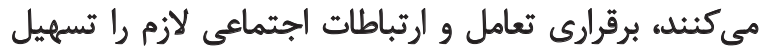

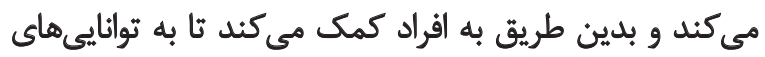

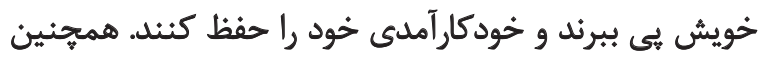

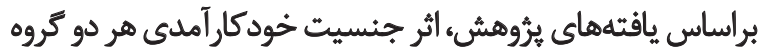

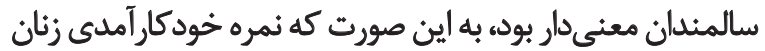

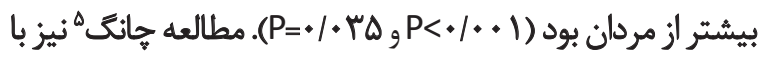

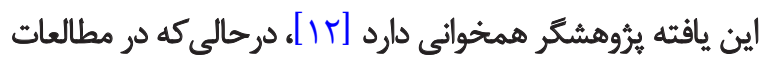

\section{McDougall}

5. Chang 
جدول F. رابطه خودكار آمدى و احساس تنهايي با برخى متغير هاى زميئه اي.

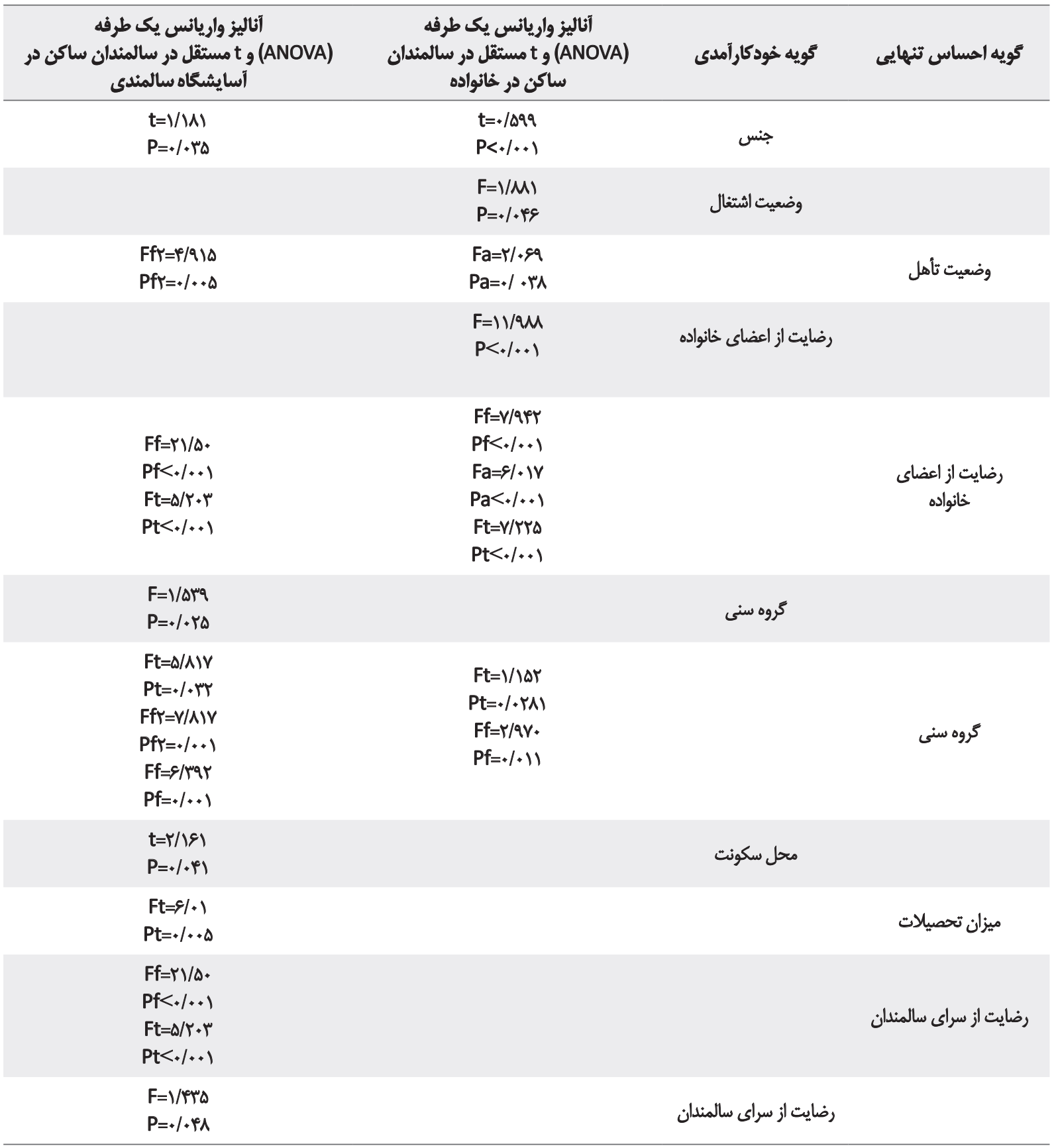

L

f: احساس تنهايى ناشى از ارتباط با خانواده، t: احساس تنهايى كلى، a: احساس تنهايى ناشى از نشائه هاى عاطفى، :fY: احساس تنهايى ناشى از ارتباط با دوستان.

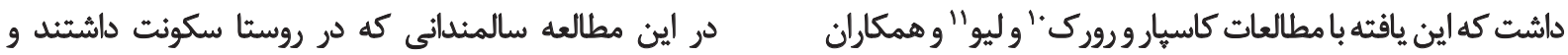

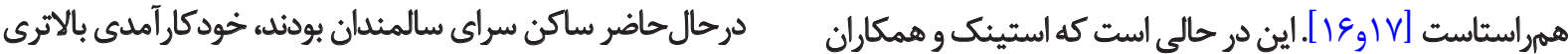

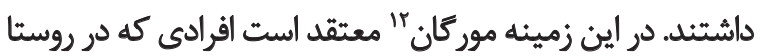

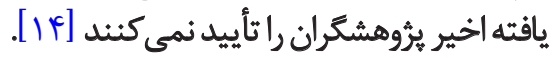

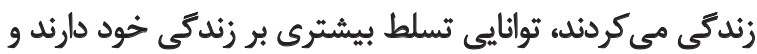

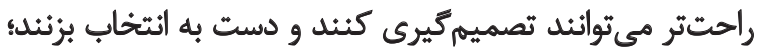


نمي شود و از رابطه با آنها راضى نيستند، بالاتر است [ IV] در اين يُروهش در گروه سالمندان ساكن خانواده، بين گروه

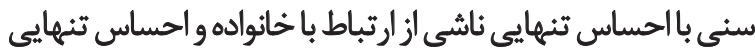

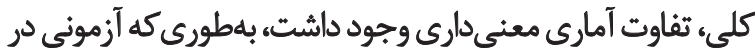

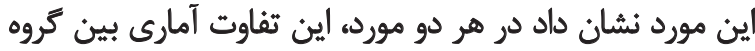

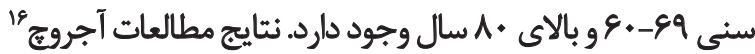

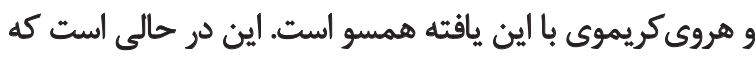

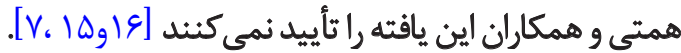

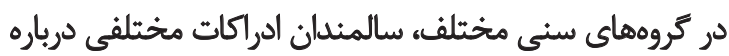

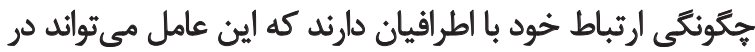

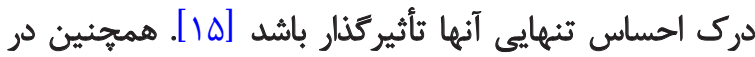

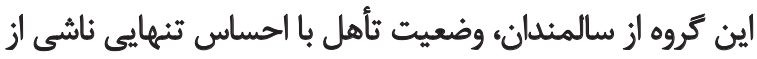

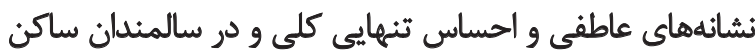

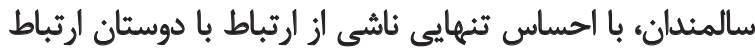

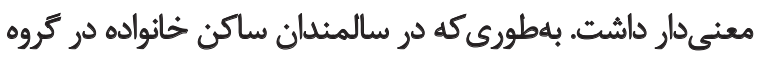

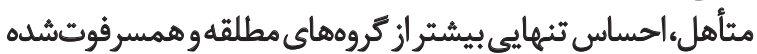

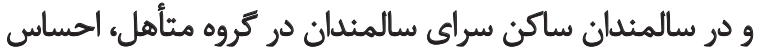

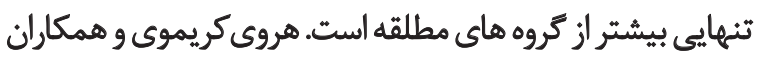
و آجروج نيز اين يافته راتأييد مي كنيند [موائ.

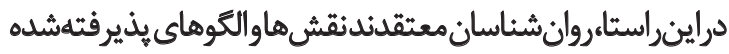

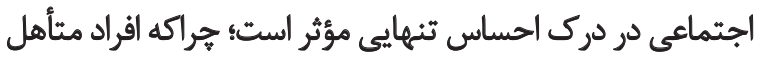

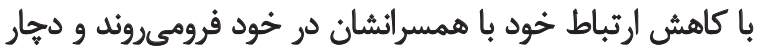

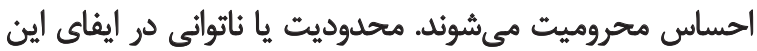

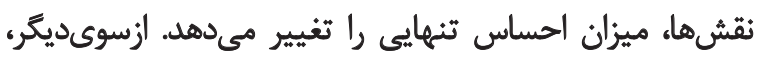

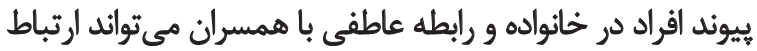

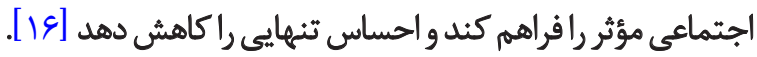
براساس يافتههاي بهدستآمده در سالمندان ساكن خانواده،

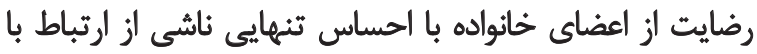

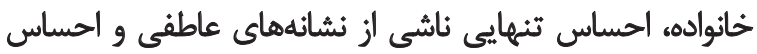

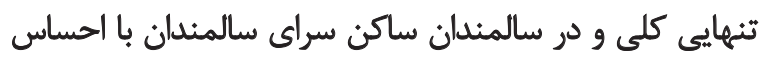

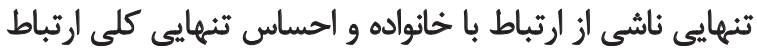

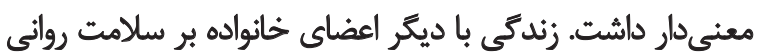
سالمندان تأثير مثبت دارد.

هروى كريموى و همكاران در برُوهش كيفى خود به اين نتيجه

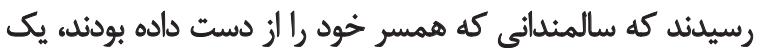

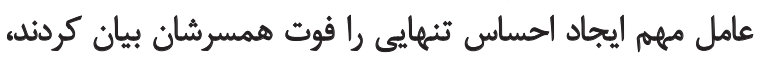

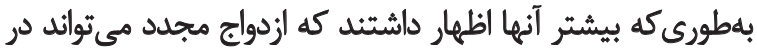

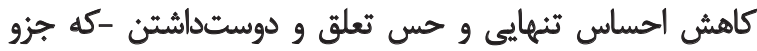

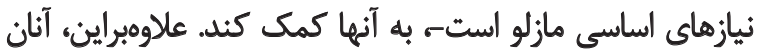

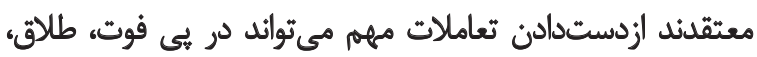

16. Ajrouch
بنابراين، زمانى كه به هراكز سالمندى منتقل ميشئود با ابعاد

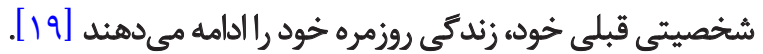
سالمندان باكروه سنى بالاتر در سراي سالمندى، خودكار آمدى

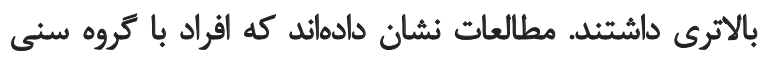

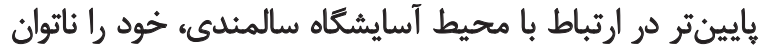

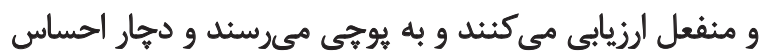

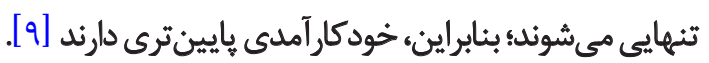
يافتههاي اين مطالعه نشان داد كه بين سالمندان ساكن خانه

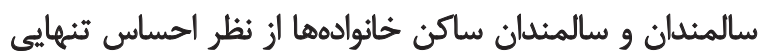

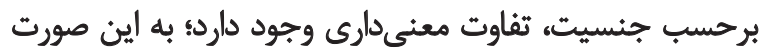

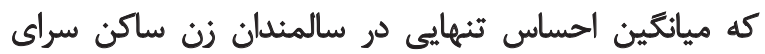

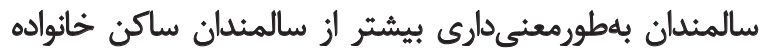

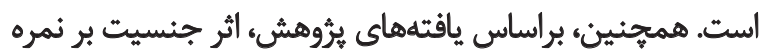

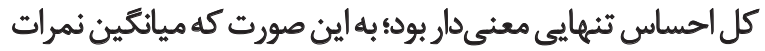
الحساس تنهايى زنان بيشتر از مردان بودائ

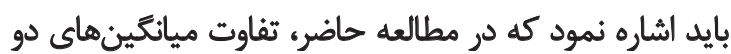

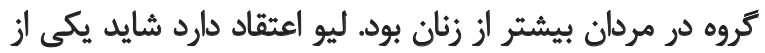

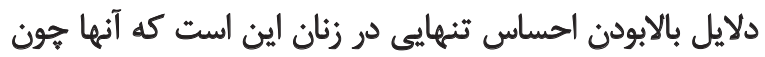

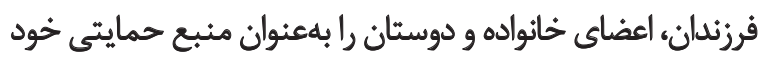

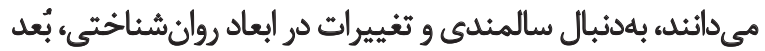

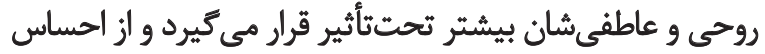

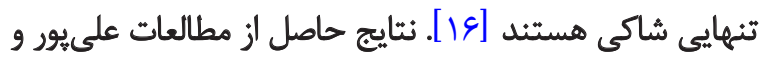

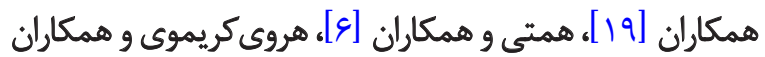

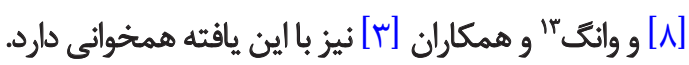
بالابودن احساس تنهايى سالمندان ساكن سراى سالمندان

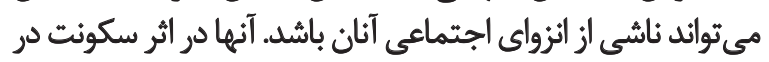

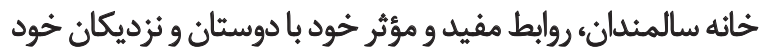

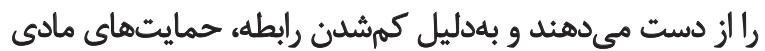

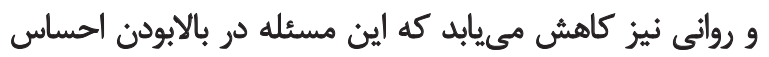

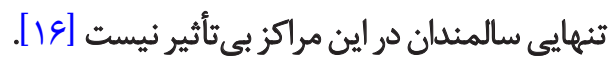
براساس يافتههاى يثروهش، در سالمندان ساكن خانوادهها

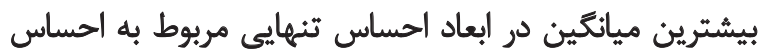

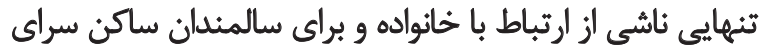

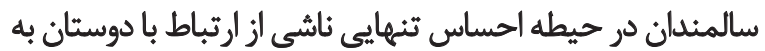

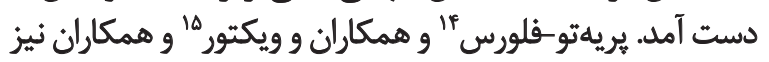

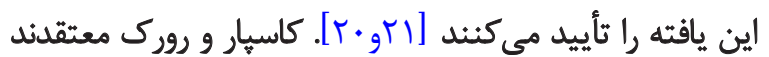

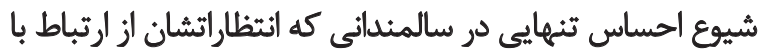
فرزندان در خانواده و ملاقات با دوستانشان در آسايشعاه برآورده آنتاطي

\section{Wang}

14. Prieto-Flores

15. Victor 
مابكو" بيرامون اين موضوع با مطالعه حاضر همسو است [Tr]. نتيجلكيرىنهبايى

با توجه به بإيينبودن ميانگين نمره خودكارآمدى سالمندان

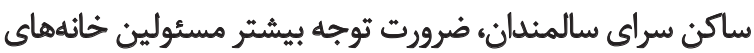

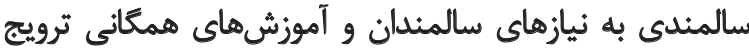

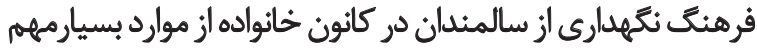

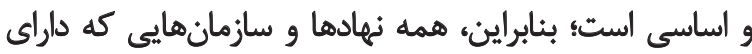

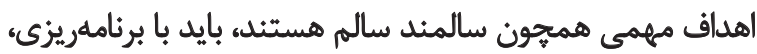

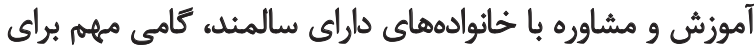

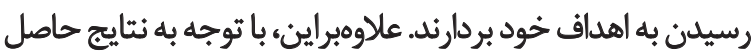

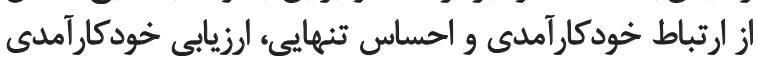

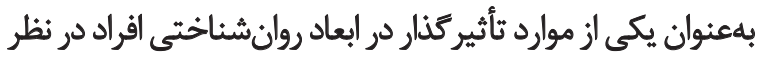

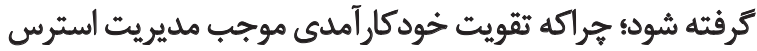
و بهبود سلامت روانى خواهد شد. تُوند

در مطالعه حاضرء ازآنجايى كه تنها سالمندان موردبررسي قرار

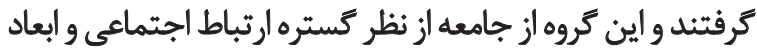

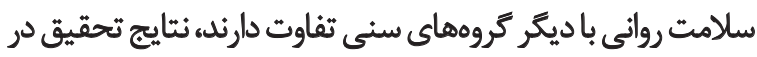

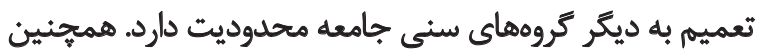

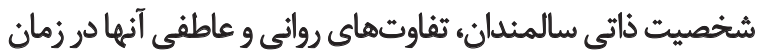

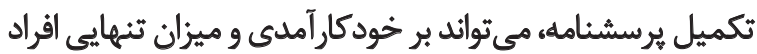

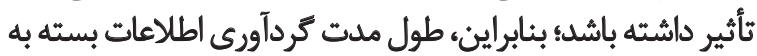
ظرفيت تحمل آنها متفاوت در نظر كرفته شده بورئ بودي

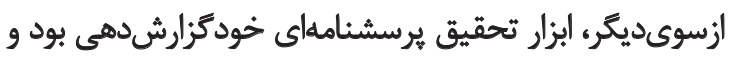

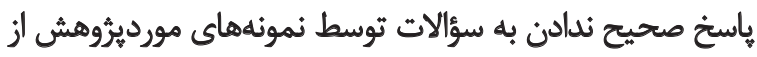

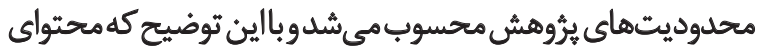

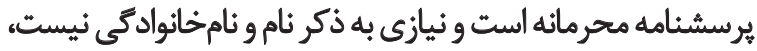

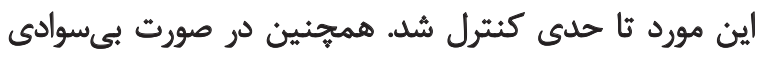

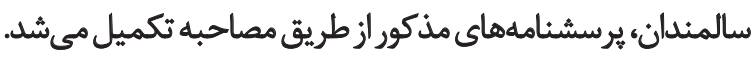

$$
\text { تشكر وقبدراني }
$$

اين مطالعه مربوط به طرح بروهشى مصوب معاونت تحقيقات

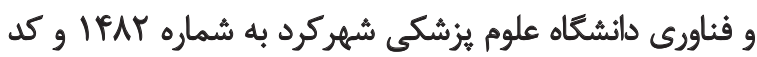

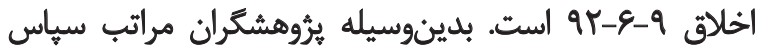

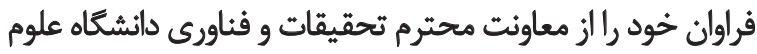

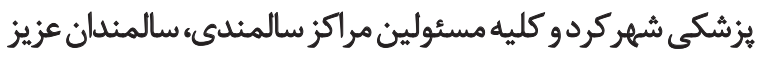

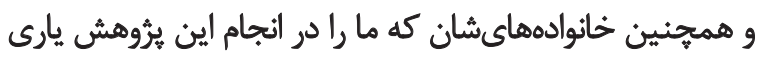

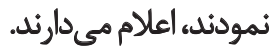

رهاشدگى يا فقدان حمايتهاى عاطفى وخانوادگى ايجاد شود [19]. نتايج بلددست آمده نشان مي دهد بين نمره كلى احساس تنهاييى

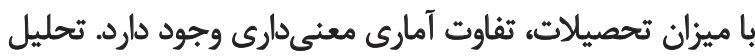

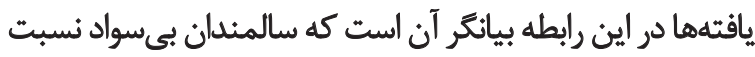

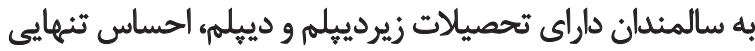

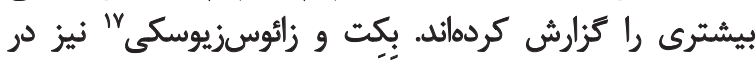

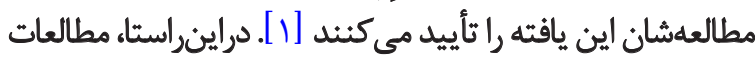

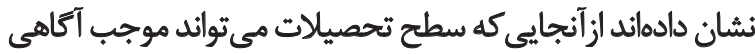

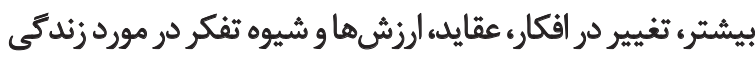

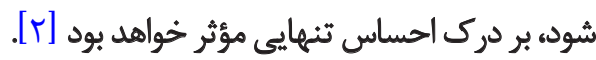

براساس نتايج بهدستآمده، در سالمندان ساكن آسايشعاه

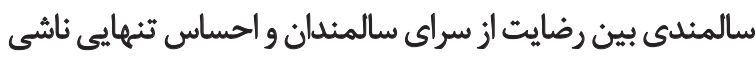

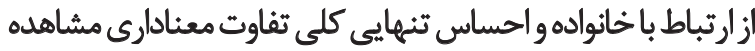

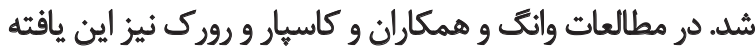

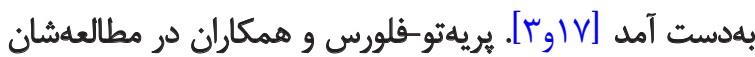

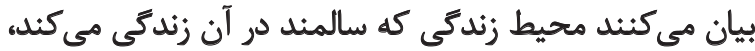

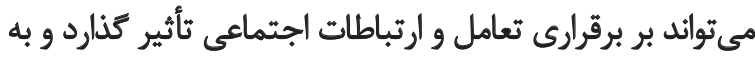

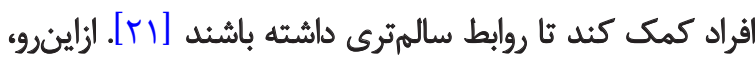

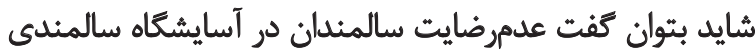

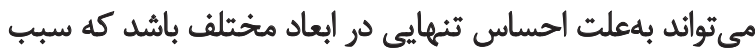
كوشه كيرى و انزواي آنها خواهد شد. تئد

برايناساس، نتايج اين بخش از مطالعه مي تواند بهمنظور بهيبود

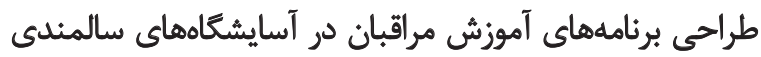

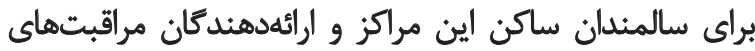

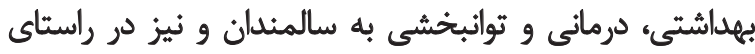

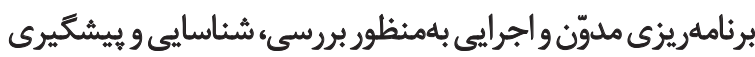
از بديده احساس تنهايى و بهببود سلامت رواني به كار كرفته شود. بردي نتايج ضريب همبستكى اسييرمن نشان داد كه در سالمندان

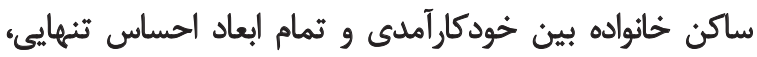

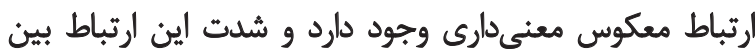

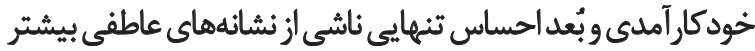

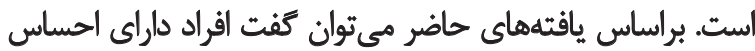

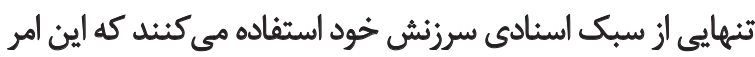

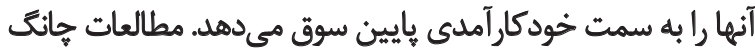

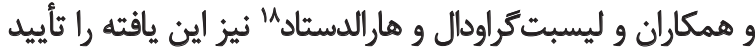

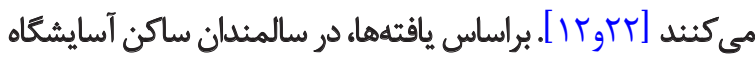

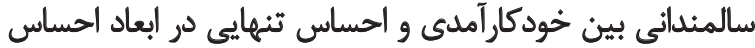

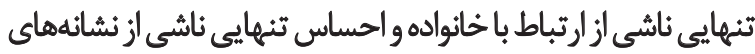

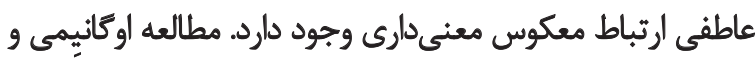

17. Bekhet and Zauszniewski

18. Lisbeth Gravdal and Haraldstad 


\section{References}

[1] Bekhet A, Zauszniewski J. Mental health of elders in retirement communities: Is loneliness a key factor? Archives of Psychiatric Nursing. 2012; 26(3):214-224.

[2] Sheybani F, Pakdaman SH, Dadkhah A, Hasanzadeh M. [Influence Music therapy on depression and loneliness in elders (Persian)]. Iranian Journal of Ageing. 2010; 5(2):54-60.

[3] Wang G, Zhang X, Wang K, Li Y, Shen O, Hang W. Loneliness among the rural older people in Anhui, China: Prevalence and associated factors. Journal of Geriatrics Psychiatry. 2011; 27(3):120132

[4] Heidari M, Shahbazi S. [Effect of Self-Care Training Program on Quality of Life of Elders (Persian)]. Iran Journal of Nursing. 2012; 25(75):1-8

[5] Kobalava P, Kotovskaya Y, Moiseev V. Efficacy and acceptability of indapamide sustained release in elderly high-risk hypertensive patients. Annals of Behavioral Medicine. 2008; 15(4):275-282.

[6] Hemati G, Dehshiry G, Shojaei S, Hakimi E. [Comprative lonliness and general health in elders with family and residential care in North on Tehran (Persian)]. Iranian Journal of Ageing. 2009; 8(3):557-564

[7] Ajrouch K. Social Isolation and Loneliness among Arab American elders: Cultural, social, and personal factors. International Journal of Aging Human Development. 2008; 5(1):44-59.

[8] Heravi-Karimooi M, Rejeh N, Foroughan M, Vaismoradi M. Experience of loneliness in Iranian abused elders. International Nursing Review. 2011; 10(6):139-145.

[9] Torki Y, Hajikazemi E, Bastani F, Haghani H. [General self efficacy in Elderly living in Rest-Homes (Persian)]. Iran Journal of Nursing. 2011; 24(73):55-62.

[10] Callaghan D. Healthy behaviors, self-efficacy, self-care, and basic conditioning factors in older adults. Journal of Community Health Nursing. 2010; 22(3):169-178.

[11] McDougall G, Montgomery K, Eddy N, Jackson E, Nelson E, Stark T, et al. Aging memory self-efficacy: Elders share their thoughts and experience. Geriatric Nursing. 2007; 24(3):162-168.

[12] Chang S, Crogan N, Wung Sh. The self-care self-efficacy enhancement program for Chinese nursing home elders. Journal of Community Health Nursing. 2007; 28(1):31-36.

[13] Lam S, Tracz S, Lucey Ch. Age, gender, and ethnicity of counselor trainees and corresponding counseling self-efficacy: Research findings and implications for counselor educators. International Journal for the Advancement of Counseling. 2012; 70(2):562-573.

[14] Steinke E, Wright D, Chung M, Moser D. Sexual self-concept, anxiety, and self-efficacy predict sexual activity in heart failure and healthy elders. Journal of Acute and Critical Care. 2008; 37(5):323-333.

[15] Paul D, Bradley J. Cardinal. Erratum to: Self-efficacy mediates the relationship between behavioral processes of change and physical activity in older breast cancer survivors. Breast Cancer. 2013; 20(1):53-60.

[16] Liu LJ, Guo Q. Loneliness and health-related quality of life for the empty nest elderly in the rural area of a mountainous county in China. Quality of Life Research. 2007; 16(8):1275- 80.
[17] Caspar S, Rourke N. The influence of care provider access to structural empowerment on individualized care in long-termcare facilities. American Journal of Physical Medicine \& Rehabilitation. 2008; 25(2):46-53.

[18] Morgan A, Levi N, Bernie C. Increasing self-efficacy the effectiveness of a pain management program for children and parents. Pediatric Rheumatology. 2011; 9(1):14-18.

[19] Alipour F, Sajadi H, Forouzan A, Biglarian A, Jalilian A. [Quality of life in elderly region 2 Tehran (Persian)]. Iranian Journal of Ageing. 2008; 3(3-4):75-83.

[20] Victor C, Burholt V, Martin W. Loneliness and ethnic minority elders in Great Britain: An exploratory study. Journal of CrossCultural Gerontology. 2012; 27(1):65-78.

[21] Prieto-Flores M, Mayoralas G, Forjaz M, Rojo-Perez F, Martinez-Martin F. Residential satisfaction, sense of belonging and loneliness among older adults living in the community and in care facilities. International Journal of Aging Human Development. 2011; 17(6):1183-1190

[22] Lisbeth Gravdal K, Haraldstad K. Associations between general self-efficacy and health-related quality of life among 12-13-yearold school children: Across-sectional survey. Health and Quality of Life Outcomes. 2009; 7(2):85-89.

[23] Ogunyemi AO, Mabekoje SO. Self efficacy, risk-taking behavior and mental health as predictor, of personal growth initiative among university undergraduates. Journal of Research in Educational Psychology. 2007; 5(2):349-362. 